\title{
Relationship of sociodemographic factors to blood lead concentrations in New Haven children
}

\author{
ALICE D STARK, ${ }^{1 *}$ RUTH FITCH QUAH, ${ }^{1} \mathrm{~J}$ WISTER MEIGS, ${ }^{1}$ AND EDWARD \\ R DELOUISE ${ }^{2}$ \\ From the Department of Epidemiology and Public Health, ${ }^{1}$ Yale University, and New Haven Department of \\ Health, ${ }^{2}$ New Haven, Connecticut 06520, USA.
}

SUMmaRY From September 1974 to 28th February 1977 80\% of the children in New Haven, Connecticut, aged from 1 month to 72 months were screened for blood lead concentrations. This report examines the relationship of several socioeconomic factors to blood lead concentrations. In addition, a set of hypotheses regarding the effect of environmental and social factors on blood level concentrations in racially defined groups was tested. Characteristics associated with increased blood lead concentrations were found to be those that tend to impair the ability of a family to provide the necessary care and supervision for a young child. The risk factors, however, produce different effects on the various race groups. The analyses support the belief that the elimination of childhood lead poisoning as a public health problem will require recognition of social-demographic and family operational factors that underlie the interactions of childhood behaviour and environmental lead potentially available to children.

From September 1974 to February 1977, a Federally supported screening and control programme for childhood lead poisoning was carried out by the health department of the City of New Haven. This programme ${ }^{1}$ provided detailed information on 8334 children in the age group 1 to 72 months and represented about $80 \%$ of the entire population of this age. An earlier report $\dagger$ showed that of the demographic factors, age and race were the most important predictors of blood lead concentration.

An in-depth study of a subset of these 8334 screened children was carried out to obtain estimates of the distributions of lead sources accessible to children and the relationship of these levels to children's blood lead concentrations. Several results of interest emerged. $\neq$ The most striking finding

-Present address: Bureau of Toxic Substances Management, New York State Department of Health, Rockefeller Plaza, Tower Building, Room 359 Albany, New York 12237.

tThe age of highest risk was from 25 to 36 months old, while the racial group with the highest risk was black. Socioeconomic status (SES) had a somewhat smaller effect, independent of age and race.

¥Environmental lead was present in all geographical areas of New Haven in amounts great enough to be hazardous if taken into the body. The environmental lead concentrations did not follow a direct trend in relation to SES. Blood level concentrations followed a direct trend with highest concentrations in children in the lowest SES. Exterior sources of lead explained more of the variation in blood lead concentrations than did interior sources. regarding environmental factors, however, was that when they were incorporated into an additive multiple regression model, a maximum of only $10 \cdot 5 \%$ of variation was explained by environmental factors. This indicates that exposure alone did not explain most of the variation that occurred in the population.

The existence of lead sources in a child's environment is necessary but is only one factor in lead poisoning. The raising of a child's blood lead concentration requires actual intake into the body, chiefly by ingestion of lead-containing materials. This is usually repeated over a long period. The social conditions that favour the ingestion of environmental lead have been examined extensively by several authors. The characteristics found to be associated with increased risk are: low socioeconomic status, ${ }^{2-5}$ disturbed mother-child relationship, ${ }^{4} \mathrm{7}$ frequent moves, ${ }^{8-10}$ single parent families, 310 underemployment, ${ }^{351112}$ large family size, ${ }^{1113}$ inadequate parental supervision, ${ }^{12}{ }^{13}$ and cultural acceptance or encouragement of oral gratification as a means of relieving anxiety. ${ }^{414}$ Many authors have suggested that the high incidence of raised blood lead concentrations among black children is the result of greater numbers of high-risk factors among the black population. $^{311}$ To sum up, the greatest risk for 
increased lead absorption in children occurs in families with problems that interfere with child rearing.

This report examines the relationships of some of these socioeconomic factors to blood lead concentrations in the New Haven study population. In particular, the following variables are considered: socioeconomic status, duration of stay at address of residence, number of parents in the household, employment status of parent(s), number of children 72 months or younger in the household, possession of a telephone, source of health care, ownership of dwelling unit, overall condition of housing, race, and day-care attendance. In addition, a procedure that focused on specific aspects of child supervision as well as environmental availability of lead within defined population groups was developed. This entailed a set of tests of specific hypotheses. Each test was designed to answer the question of whether or not a particular factor, related to either the physical or social environment, was associated with variation in blood lead concentration in a particular population of children.

\section{Materials and methods}

INITIAL ANALYSIS

Initial analyses of the relationship of social/economic factors to blood lead concentrations were carried out on the $\mathbf{8 3 3 4}$ children described in the introduction. Of these children, 377 were used to make up the defined population groups on whom specific hypotheses were tested. This subset will be described in detail in the next section.

The variables examined and the sources and reliability of each of them are described in table 1.
HYPOTHESIS TESTING

Out of the 8334 children described above a subset was selected for participation in our in-depth environmental lead exposure study. The subset was used in this study as well, and was composed of 377 children each of whom had resided at the same address for at least one year and each of whom had had at least two blood-lead determinations during that year. Both tests had to fall in one of the three categories $\leqslant 29 \mu \mathrm{g} / \mathrm{dl} \mathrm{Pb}, \quad 30-39 \mu \mathrm{g} / \mathrm{dl} \mathrm{Pb}$, or $\geqslant 40 \mu \mathrm{g} / \mathrm{dl} \mathrm{Pb} .^{15}$ Initially, 784 of the 8334 screened children were eligible for inclusion in the subset, but 407 had to be excluded either because the family moved before attempted inspection by the project sanitation officer or the parents refused to allow inspection by him. The homes of the 377 children in the subset were tested for the concentration of lead in house dust, in interior and exterior paint, and in soil both close to the structure and close to the street. Socioeconomic status and air lead concentration were derived for each child from his/her census tract of residence. Water lead was not considered. All water in New Haven was supplied by a single source (lead content $0.01 \mathrm{ppm}$ ) which meets the Public Health Service standard. A sample of $2 \%$ of home water supplies was analysed for lead during the routine investigation of households where a child with a raised body burden of lead resided; all were negative.

Our examination showed that environmental lead concentrations were generally not good predictors of children's blood lead concentrations. Nevertheless, because we did find that age and race were highly associated with blood lead concentrations it seemed reasonable to explore the possibility that the effect of environmental or social factors might vary depending on the age and race of

Table 1 Sources, availability, and estimated reliability of variables used for the study of children's blood lead concentrations, New Haven, Connecticut, September 1974-February 1977

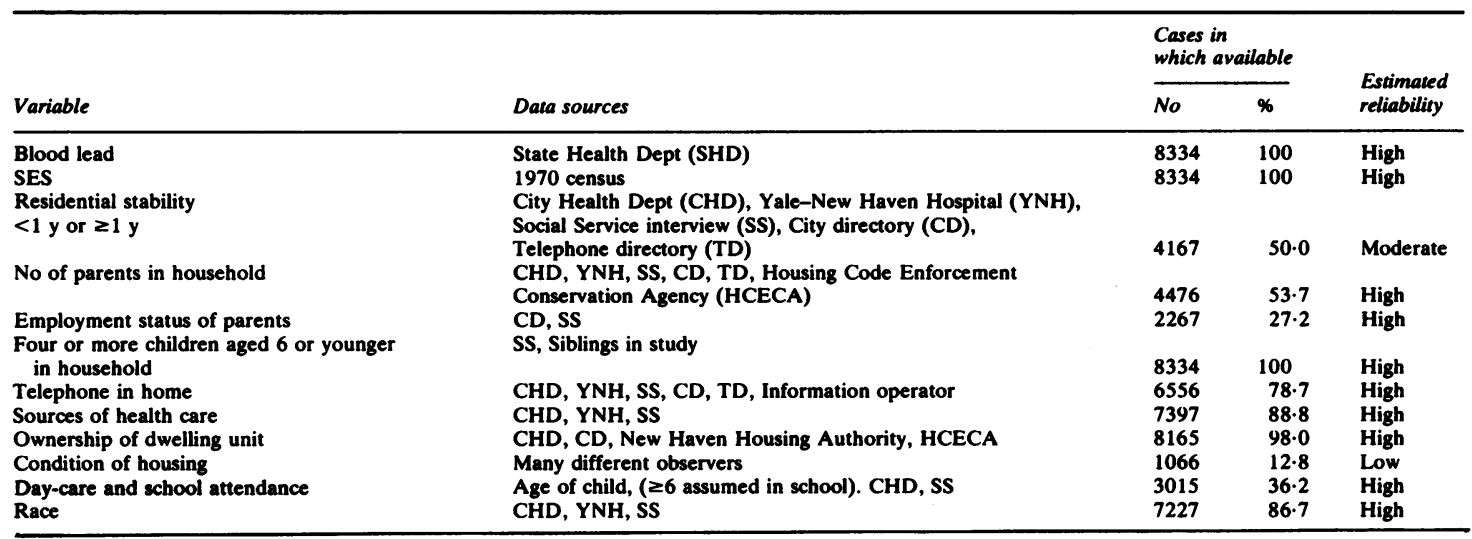


the population at risk. Disaggregation of the subset of 377 children into race-age subgroups resulted in unacceptably small sample sizes. Therefore, the subset was divided into three racial group-black, white, and Hispanio-to test the hypothesis that exposure to lead does result in a statistically significant increase in blood lead concentration. Each environmental lead source was classified as hazardous or not hazardous based on the standards suggested or established by the US Environmental Protection Agency. ${ }^{18}$ Children were then grouped by hazard category, and geometric mean blood lead concentrations were computed and tested for statistical equality using Student's $t$ test on the log-transformed data. ${ }^{17}$

In a similar manner several social variables, such as day-care attendance, single parent family, working single parent family, and sibship size, were tested. Tests were performed on groups stratified by race, and within each racial group those exposed and not exposed to the risk factor were compared statistically.
Results

The results shown in tables $2-4$ are based on varying proportions of the 8334 children. Table 2 presents the results from $t$ test analysis. The following variables were examined: duration of stay at address of residence (under one year or one year or more); number of parents in the household (one or two); employment status of parent(s) (none or at least one employed); number of children 6 years or younger in the household, small family (defined as up to three children in family) or large (defined as four or more children); possession of a telephone (yes or no); source of health care (public or private); and attendance at day care or school (yes or no).

Table 3 presents the results from analysis of variance of the following variables: socioeconomic status (levels 1 to 5); ownership of dwelling unit (privately owned, private rent, public rent, or public lease); overall condition of housing (good, fair, or poor); race (black, white, Hispanic).

Table 2 Comparison of geometric mean blood lead concentrations between groups with and without suspected risk factors. New Haven, Connecticut, September 1974-February 1977

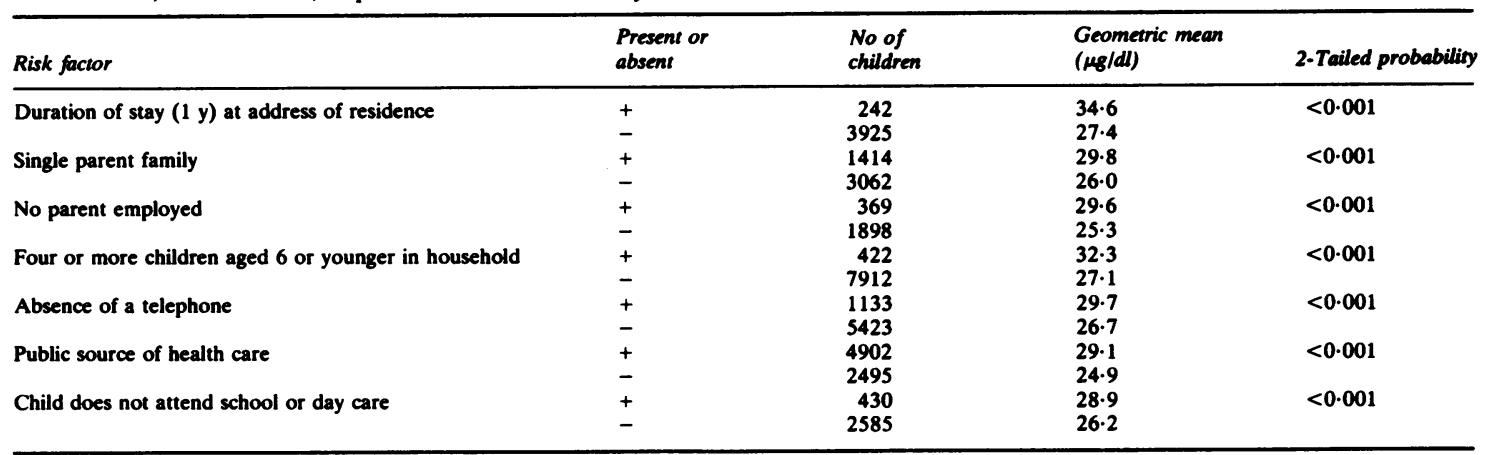

Table 3 Comparison of geometric mean blood lead concentrations between groups in differing categories of risk factors, New Haven, Connecticut, September 1974-February 1977

\begin{tabular}{|c|c|c|c|c|}
\hline Risk factor & Category & No of children & $\begin{array}{l}\text { Geometric mean } \\
\text { blood lead } \\
\text { concentration } \\
(\mu \mathrm{d} / \mathrm{dl})\end{array}$ & $\begin{array}{l}\text { 2-Tailed } \\
\text { probability }\end{array}$ \\
\hline Socioeconomic status & $\begin{array}{l}1 \\
2 \\
3 \\
4 \\
5\end{array}$ & $\begin{array}{r}967 \\
593 \\
1813 \\
2479 \\
2482\end{array}$ & $\begin{array}{l}22 \cdot 5 \\
26 \cdot 1 \\
26 \cdot 7 \\
29 \cdot 1 \\
29 \cdot 1\end{array}$ & $<0.001$ \\
\hline Ownership of dwelling unit & $\begin{array}{l}\text { Owned } \\
\text { Private rent } \\
\text { Public rent } \\
\text { Public lease }\end{array}$ & $\begin{array}{r}624 \\
6298 \\
1143 \\
100\end{array}$ & $\begin{array}{l}25 \cdot 4 \\
27 \cdot 8 \\
26 \cdot 9 \\
30 \cdot 1\end{array}$ & $<0.001$ \\
\hline Over-all condition of housing & $\begin{array}{l}\text { Good } \\
\text { Fair } \\
\text { Poor }\end{array}$ & $\begin{array}{l}516 \\
369 \\
181\end{array}$ & $\begin{array}{l}29 \cdot 6 \\
33 \cdot 9 \\
34 \cdot 5\end{array}$ & $<0.001$ \\
\hline Race & $\begin{array}{l}\text { Black } \\
\text { White } \\
\text { Hispanic }\end{array}$ & $\begin{array}{l}3923 \\
2106 \\
1198\end{array}$ & $\begin{array}{l}29 \cdot 6 \\
23 \cdot 9 \\
27 \cdot 9\end{array}$ & $<0.001$ \\
\hline
\end{tabular}


Table 4 presents the proportions of children in each SES level who possess the high-risk factors found to be important in tables 2 and 3-that is, duration of stay at residence under one year, single parent family, unemployment, four or more children aged 6 or under in the household, no telephone in the household, use of a public source of health care, residence in a publicly leased dwelling unit, poor overall housing condition, and being black. These results could have been influenced by a difference in the age distribution of children within each SES level. In SES 1 mean age was 3.98 years and geometric mean blood lead concentration was $22.5 \mu \mathrm{g} / \mathrm{dl}$, while in SES 2 these values were 3.64 and 26.1; in SES 3 , 3.50 and $26 \cdot 7$; SES $4,3 \cdot 40$ and $29 \cdot 1$; and SES 5, 3.24 and $29 \cdot 1$.
Because four or more children aged under 6 in a family was identified as a risk factor, and because attendance at school or day-care appears to be protective, the interaction of these factors was explored. When families were divided by the number of children in them, there were significantly $(p<0.001)$ lower mean blood lead concentrations in children in both large and small families where the screened child attended day-care. Even when the screened child attended day-care, children in large families had significantly $(p<0.001)$ higher mean blood lead concentrations than did children in small families. This indicates the independent contribution of both day-care attendance and family size to variation in children's blood lead concentrations.

Table 5 shows the changes in mean blood lead

Table 4 Number and percentage* of children with high risk factors within each SES, New Haven, Connecticut, September 1974-February 1977

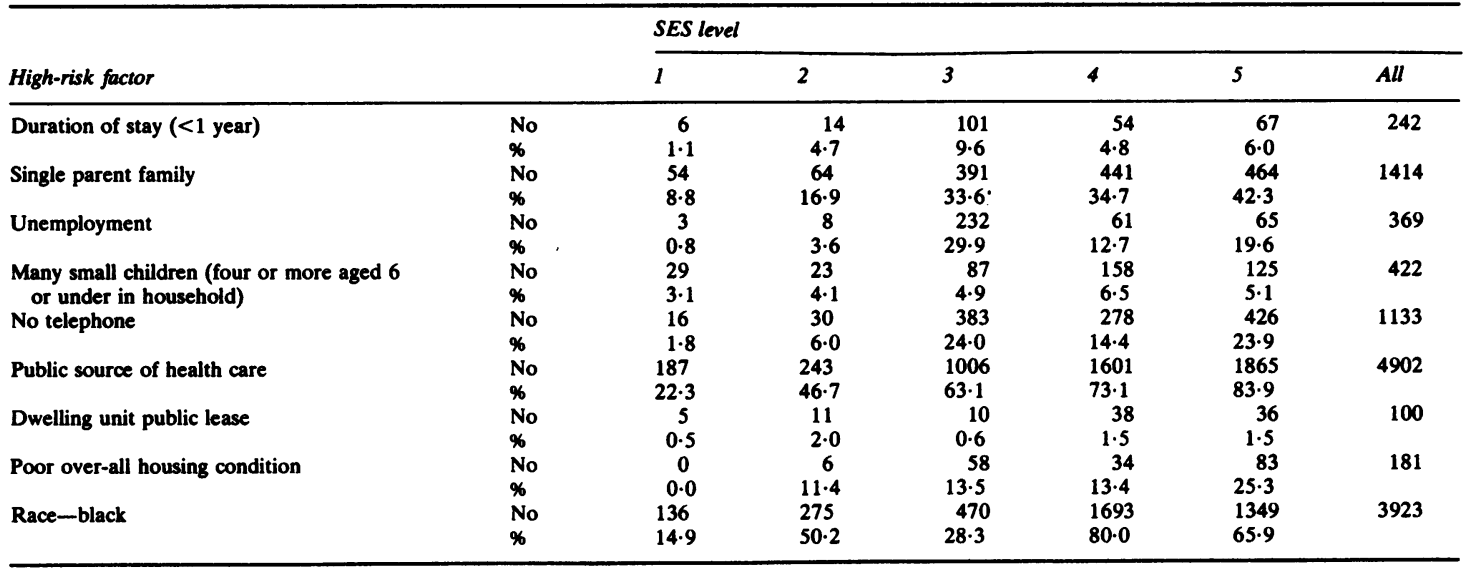

*Number of children within each SES with the risk factor was divided by the total number of children for whom we had information about that risk factor in that SES and multiplied by 100 to give the percentage of children with the risk factor. For example, we had information about number of parents in the home for 614 children in SES 1 . Of these 54 or $8.8 \%$ were single parent families.

Table 5 Geometric mean blood lead concentrations by race, ${ }^{*}$ age, and time of initial testing, New Haven, Connecticut, September 1974-February 1977

\begin{tabular}{|c|c|c|c|c|c|c|c|}
\hline \multirow[b]{2}{*}{ Race } & \multirow[b]{2}{*}{ Age (months) } & \multicolumn{2}{|c|}{ September 1974-November 1975} & \multicolumn{2}{|c|}{ December 1975-February 1977} & \multirow[b]{2}{*}{$\begin{array}{l}\text { Standard error } \\
\text { of difference } \\
\text { in means }\end{array}$} & \multirow[b]{2}{*}{$\begin{array}{l}\text { Significance } \\
\text { levels }\end{array}$} \\
\hline & & $\begin{array}{l}\text { No of } \\
\text { children }\end{array}$ & $\begin{array}{l}\text { Geometric mean } \\
\text { blood lead } \\
\text { concentration }\end{array}$ & $\begin{array}{l}\text { No of } \\
\text { children }\end{array}$ & $\begin{array}{l}\text { Geometric mean } \\
\text { blood lead } \\
\text { concentration }\end{array}$ & & \\
\hline Black & $\begin{array}{l}1-36 \\
37-72 \\
\text { Total }\end{array}$ & $\begin{array}{l}1039 \\
1628 \\
2667\end{array}$ & $\begin{array}{l}31 \cdot 3 \\
29 \cdot 8 \\
30 \cdot 4\end{array}$ & $\begin{array}{l}433 \\
527 \\
960\end{array}$ & $\begin{array}{l}28 \cdot 0 \\
26 \cdot 7 \\
27 \cdot 3\end{array}$ & $\begin{array}{l}0.0670 \\
0.0588 \\
0.0441\end{array}$ & $\begin{array}{l}<0.001 \\
<0.001 \\
<0.001\end{array}$ \\
\hline White & $\begin{array}{l}1-36 \\
37-72 \\
\text { Total }\end{array}$ & $\begin{array}{l}321 \\
653 \\
974\end{array}$ & $\begin{array}{l}27 \cdot 0 \\
25 \cdot 0 \\
25 \cdot 7\end{array}$ & $\begin{array}{r}388 \\
632 \\
1020\end{array}$ & $\begin{array}{l}22 \cdot 3 \\
22 \cdot 0 \\
22 \cdot 1\end{array}$ & $\begin{array}{l}0.0875 \\
0.0649 \\
0.0520\end{array}$ & $\begin{array}{l}<0.001 \\
<0.001 \\
<0.001\end{array}$ \\
\hline Hispanic & $\begin{array}{l}1-36 \\
37-72 \\
\text { Total }\end{array}$ & $\begin{array}{l}341 \\
479 \\
820\end{array}$ & $\begin{array}{l}28 \cdot 1 \\
28 \cdot 9 \\
28 \cdot 6\end{array}$ & $\begin{array}{l}186 \\
147 \\
333\end{array}$ & $\begin{array}{l}26 \cdot 6 \\
26 \cdot 9 \\
26 \cdot 7\end{array}$ & $\begin{array}{l}0 \cdot 1079 \\
0 \cdot 1116 \\
0.0769\end{array}$ & $\begin{array}{l}<0.001 \\
<0.001 \\
<0.001\end{array}$ \\
\hline Total & & 4461 & $29 \cdot 0$ & 2313 & $24 \cdot 9$ & & \\
\hline
\end{tabular}

"Race was categorised as "other" for 453 children and was missing for 1107 children. 
concentrations for each race group over the 30 full months that the screening and public education programmes were in operation. The downward trend for all groups suggest that the programme was effective either by identifying the children at highest risk first or by alerting mothers to the dangers of licking non-food items, or by a combination.

Table 6 shows the results of the tests of whether exposure to specific risk factors was associated with significant differences in blood lead concentrations in groups of children stratified by race. These groups were formed from the subset of 377 children. The test of sibship size could not be performed on the Hispanic group because there were no individuals in the small sibship size category. For each risk factor, variances for the exposed and unexposed were tested for equality using the F-test and the appropriate $t$ test was then performed.

It can be seen that hazardous lead exposure was highly significant $(p=0.0001)$ for black children but was non-significant $(p=0.59)$ for white children and $(p=0.99)$ for Hispanic children. White children who were exposed had higher concentrations than those not exposed but Hispanic children's blood concentrations were identical, regardless of exposure.

The effect of day-care attendance was non-significant $(p=0.43)$ for black children, and the non-attenders had a slightly lower mean blood lead concentration than did the attenders. For white children day-care attendance was associated with a significantly $(p=0.04)$ favourable result. The effect of day-care attendance on Hispanic children's blood lead concentrations was non-significant $(p=0.43)$, but attenders had, on the average, lower concentrations than non-attenders.

For black children the effect of having an unemployed single parent was non-significant $(p=0.74)$, but the children living in unemployed single parent households had higher blood lead concentrations than children not living in such households. Living in unemployed single parent households was highly significant $(p=0.005)$ for white children whose concentrations were much higher than those not living in such households. The effects of living in an unemployed single parent household was non-significant $(p=0.74)$ for Hispanic children who on the average had lower concentrations living in such households.

For black children there was no effect $(p=0.99)$ from sibship size, and mean blood lead concentrations were identical for both large and small sibships. The effect was highly significant $(p=0.01)$ for white children with children having small sibship also having lower blood lead concentrations.

The effect of having one parent in the household was non-significant for all three groups. Nevertheless, the results for white families should be interpreted cautiously because of the small number of single parent families. Blood lead concentrations for blacks $(p=0.60)$ were higher in single than in two parent families; for whites $(p=0.43)$ higher in single than in two parent families; and for Hispanics $(p=0.74)$ lower in single than in two parent families.

\section{Discussion}

The characteristics associated with increased blood lead concentrations are those that tend to impair the ability of a family to provide the necessary care and supervision for a young child. The relationship of these characteristics is not always directly with SES, which mayindicate unequalimportance of factorsordiffering coping patterns within segments of the population. For example, high mobility, high unemployment, and

Table 6 Effect of exposure to risk factors on children's blood lead concentrations by race, New Haven, Connecticut, September 1974-February 1977

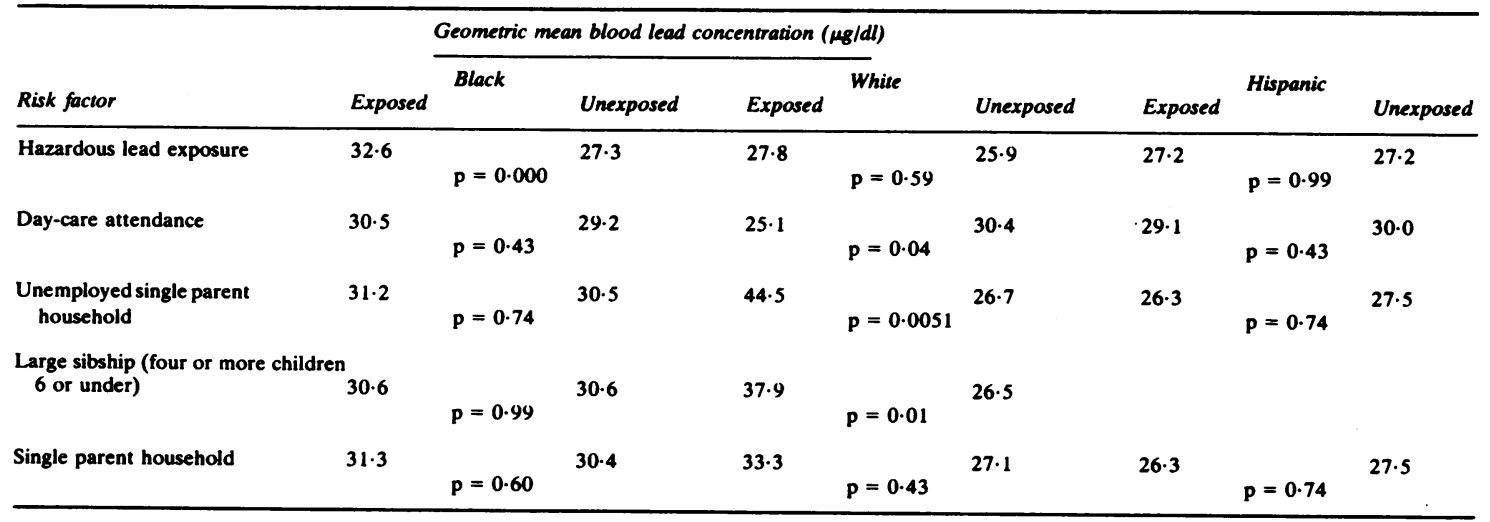


a large proportion of households without a telephone are found in SES 3. SES 3, however, has a geometric mean blood lead concentration well below that found in SES 4 and 5 although SES 4 and 5 fare better on the mobility, unemployment, and telephone factors.

We have seen that mean age of children tested decreases with decreasing SES while geometric mean blood lead concentration increases. The effect of age has been well established and, in fact, has been described for the New Haven population elsewhere. ${ }^{17}$ The other factors associated with SES are single parent family, public source of health care, and poor overall housing condition. Racial distribution is not directly related to SES, which leads to the question of whether factors related to race but not necessarily related to SES may contribute to increased risk of raised blood lead concentrations in black children. Such factors might include dietary or cultural patterns that favour ingestion and absorption of lead. The decline over time in mean blood lead concentrations seen in all racial groups suggests that the New Haven Health Department's public education and screening programme might have been effective in reducing the lead burden in the city's paediatric population.

Despite considerable variation within race groups, analysis of variants suggest that the risk factors produce different effects among the three race groups. For black children lead exposure per se was of significance whereas the social factors were not. This may mean that in the black special-study population, patterns of child care were not substantially affected by economic level, family size, or number of parents in the household. In addition, it may be possible that licking behaviour is widespread in these black families. In contrast, for white children, day-care attendance, single unemployed parent household, and sibship size were significant while exposure was not. The supervision of the young white child appears to be modified by the presence of poverty and large numbers of young children in the household. This result is in agreement with the family models described in sociological publications. ${ }^{18} 19$ Licking behaviour in this group appears not to be pervasive, but is limited to children in poorer, larger families. None of the factors was significant for Hispanic children, although it should be noted that exposure followed the white pattern as did day-care attendance. These outcomes suggest that some pervasive characteristic whether dietary or behavioural (pica) was present in black households in this study, so that lead in the environment tended to be ingested and absorbed regardless of family structure and function. In the white households the factors that interfered with child supervision were more likely to have produced an increased intake of lead. The Hispanic families appeared to interact with the environment in a manner different from that of the blacks and the whites.

These analyses support the belief that elimination of childhood lead poisoning as a public health problem will require recognition of social, demographic, and family operational risk factors that underlie the interactions of childhood behaviour and environmental lead potentially available to children. Elimination of lead from the residential environment will remain as a long-term goal. This goal will not be reached for some years in cities like New Haven, where lead is widely dispersed throughout the residential environment, both outdoors and indoors. The hazard occurs when the family is unable to monitor the activities of its youngest members and thereby protect them from excessive ingestion of lead. When this situation is further complicated by pica in the child, the risk of lead poisoning increases rapidly. It is in this group that particular social, demographic, and family operational risk factors must be faced by health authorities if childhood lead poisoning is to be controlled in the near future.

This work was supported in part by grant No 01-H-000278-02-0 United States Department of Health, Education and Welfare, Public Health Service and grant No 2549-RG United States Department of Housing and Urban Development.

\section{References}

${ }^{1}$ Stark AD, Meigs JW, Quah RF, DeLouise ER. Family operational co-factors in the epidemiology of childhood lead poisoning. Arch Environ Health 1978; 33: 222-5.

${ }^{2}$ Guinee VF. Lead poisoning. Am J Med 1972; 53: 283-8.

${ }^{3}$ Chatterjee P, Geltman JH. Lead poisoning: subculture as a facilitating agent. Am J Clin Nutr 1972; 25: 324-30.

4Lourie RS, Layman EM, Millican FK. Why children eat things that are not food. Children 1963; 10: 143-6.

5 Jacobnizer $H$. Lead poisoning in childhood: epidemiology, manifestations and prevention. Clin Pediatr 1966; 5: 277-86.

${ }^{6}$ Chisolm JJ Jr. Lead poisoning. In: Barnett HL, ed. Pediatrics. 15th ed. New York: Appleton, Century, Crofts, 1972.

${ }^{7}$ Chisolm JJ Jr, Kaplan E. Lead poisoning in childhood. Comprehensive management and prevention. $J$ Pediatr 1968; 73: 946-51.

- Chisolm JJ Jr. Treatment of lead poisoning. Modern Treatment 1971; 8: 593-611.

${ }^{\circ}$ Wendling $P$. Lead poisoning and the local health department. In: McCabe EB, Challon RS, eds. Highlights of the Midwest and Eastern regional conference on childhood lead poisoning. Chicago: III. Lead Product Association Inc, 1972. 
${ }^{10}$ Madden JB. The role of the community health center. In: McCabe EB. Challon RS. eds. Highlights of the Midwest and Eastern regional conference on childhood lead poisoning. Chicago: Ill. Lead Industries Association Inc, 1972.

${ }^{11}$ Meigs JW, Whitmire E. Epidemiology of lead poisoning in New Haven children-operational factors. Conn Med 1971; 35: 363-9.

${ }^{12}$ Pueschel SM, Kopito L, Schwackman H. Children with an increased lead burden. JAMA 1972; 222: 462-6.

${ }^{13}$ Browder A. Lead poisoning in children: When to take aggressive action. Resident and Staff Physician 1976 March: 107-15.

${ }^{14}$ Millican EK, Layman EM, Lourie RS, Takahasi LY. Study of an oral fixation: pica. Proceedings of the American Psychoanalytic Association 1965; May: 105.
${ }^{15}$ Quah RF, Stark AD, Meigs JW, DeLouise ER. Micro determination of blood lead: reliability for mass screening of children. Conn Med 1980; 44: 210-3.

${ }^{16}$ Air Quality Criteria for Lead. Washington, DC: US Environmental Protection Agency, 1977. (EPA-600/8-77-017).

${ }^{17}$ Aitchison J, Brown JAC. The lognormal distribution. London: Cambridge University Press, 1966.

${ }^{18}$ Rainwater L. The lower class: health, illness, and medical institutions. In: Deischer I, Thompson J. eds. Among the people. New York City: Basic Books, 1968.

${ }^{19}$ Pratt L. Family structure and effective health behaviour-the energized family. Boston, Mass: Houghton Mifflin Co. 1976. 